\title{
A CASE REPORT OF MYELOPATHY - SYRINGOMYELIA
}

\author{
A. K. Badrinath1, K. Suresh'2, R. Ragunathan'3, Suresh Babu $S^{4}$ \\ 1 Professor, Department of General Medicine, Sri Manakula Vinayagar Medical College, Kalitheerthal Kuppam, Puducherry. \\ ${ }^{2}$ Associate Professor, Department of General Medicine, Sri Manakula Vinayagar Medical College, Kalitheerthal Kuppam, Puducherry. \\ ${ }_{3}^{3}$ Associate Professor, Department of General Medicine, Sri Manakula Vinayagar Medical College, Kalitheerthal Kuppam, Puducherry. \\ ${ }^{4}$ Senior Resident, Department of General Medicine, Sri Manakula Vinayagar Medical College, Kalitheerthal Kuppam, Puducherry.
}

\section{ABSTRACT}

\section{BACKGROUND}

Syringomyelia is a rare form of myelopathy mostly affecting the cervical region of the spinal cord. It is characterised by formation of cavitation of the central part of spinal cord leading to dissociative sensory loss and motor weakness. Most of the cases occur secondary to trauma and other causes include craniovertebral anomalies and sometimes may be idiopathic. Treatment is often not satisfactory. Here, we present a 38-year-old male presenting with weakness of upper limbs with severe neck pain, diagnosed to be a case of syringomyelia.

\section{KEYWORDS}

Syringomyelia, Dissociative Sensory Loss, Cavitation.

HOW TO CITE THIS ARTICLE: Badrinath AK, Suresh K, Ragunathan R, et al. A case report of myelopathy - Syringomyelia. J. Evolution Med. Dent. Sci. 2016;5(104):7696-7698, DOI: 10.14260/jemds/2016/1736

\section{BACKGROUND}

Syringomyelia is a chronic progressive degenerative disorder of the spinal cord. It commonly involves the cervical cord region by formation of a cavity (Syrinx) but may extend into the thoracic and lumbar region or upwards into the medulla oblongata and pons (Syringobulbia). Clinically, patients present with dissociative sensory loss and brachial amyotrophy due to intramedullary spinal cord compression. It is diagnosed by clinical symptoms and signs and confirmed by imaging techniques. Treatment is mainly surgical, but is often unsatisfactory. Medical management is often for symptomatic relief.

\section{Case Report}

A 38-year-old male patient presented with complaints of weakness of all four limbs more on the right upper limb for 8 months' duration. Patient noticed weakness initially in the right upper limb followed by the left upper limb. He also had severe neck pain extending into the right shoulder and arm. He had no history of urinary disturbances, no difficulty in swallowing, and no history of trauma in the past. He is not diabetic or hypertensive. No history of similar complaints in the family members.

On examination, patient is conscious and oriented, vitals stable, and cardiac and respiratory system examination was normal. His central nervous system examination: Higher mental functions were normal. Cranial nerves were intact. Motor system: Muscle wasting present in both upper limbs, more in the right upper limb and distal more than the proximal with hypotonia. Power was $2 / 5$ in the right upper limb and $3 / 5$ in the left upper limb. Power was $4 / 5$ in both the lower limbs.

Financial or Other, Competing Interest: None.

Submission 18-04-2016, Peer Review 14-12-2016,

Acceptance 22-12-2016, Published 29-12-2016.

Corresponding Author:

Dr. A. K. Badrinath,

No. 4, Shree Apartments,

II Floor, \#29, Avvainagar

Lawspet, Puducherry-605008.

E-mail: akbsts@yahoo.co.in

DOI: $10.14260 /$ jemds/2016/1736

\section{(c) $(1)$}

Reflexes were diminished in the upper limb and exaggerated in both lower limbs and plantar bilateral extensor. Sensory system examination showed absent pain and temperature sensations in the upper limbs and extending to the face with preserved touch sensation and posterior column sensations. No ulcers in the hand. No urinary disturbances, skull and cranium normal.

The patient was further investigated and his complete haemogram and renal function tests were normal. A magnetic resonance imaging of the cervical spine with whole spine screening was performed as the patient had weakness of all 4 limbs with dissociative sensory loss and diagnosed as a case of Syringomyelia with Syringobulbia.

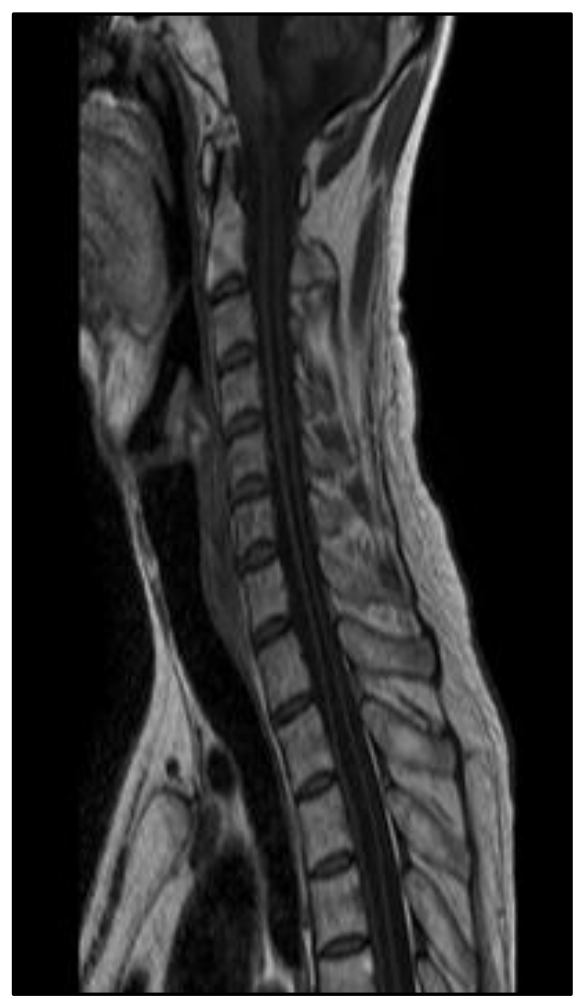

Figure 1. T1 image of the cervical spinal cord with evidence of syringomyelia. MRI whole spine 


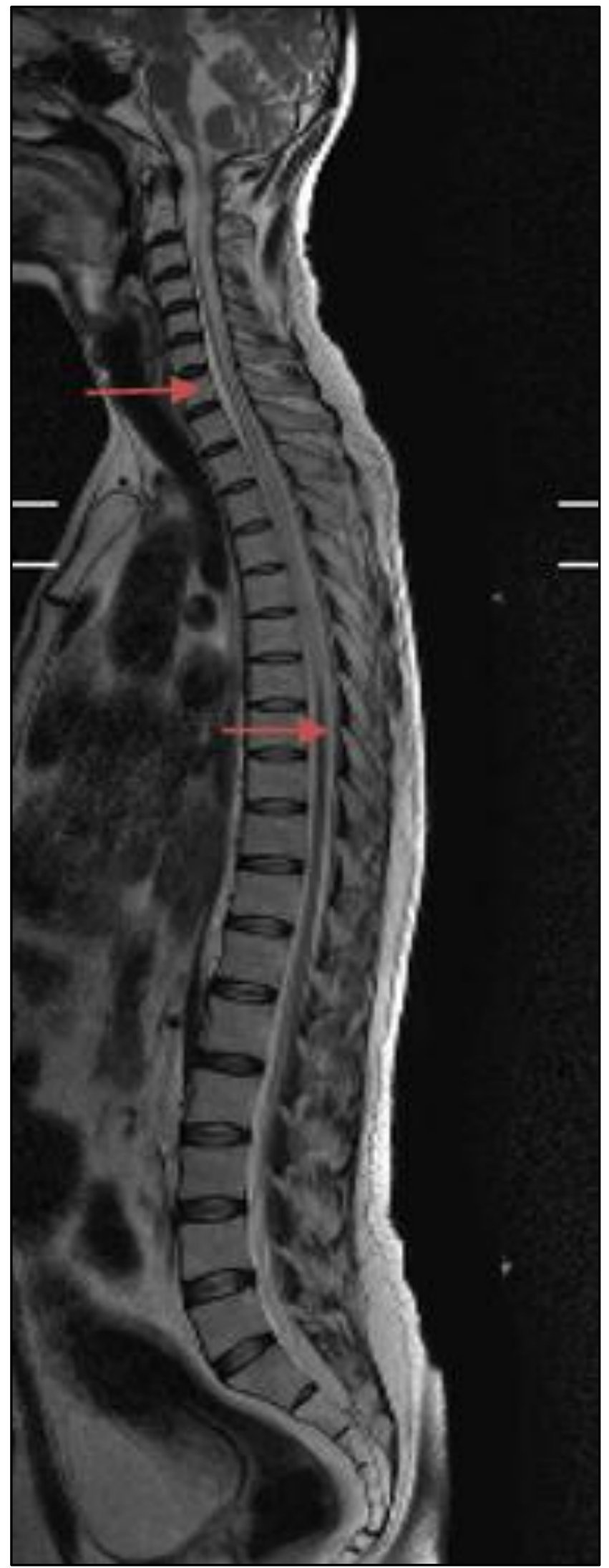

Figure 2. T2 image showing the formation of cavitation of spinal cord compressing the spinal cord extending from the cervical region to thoracic and lumbar region (Indicated by arrow mark)

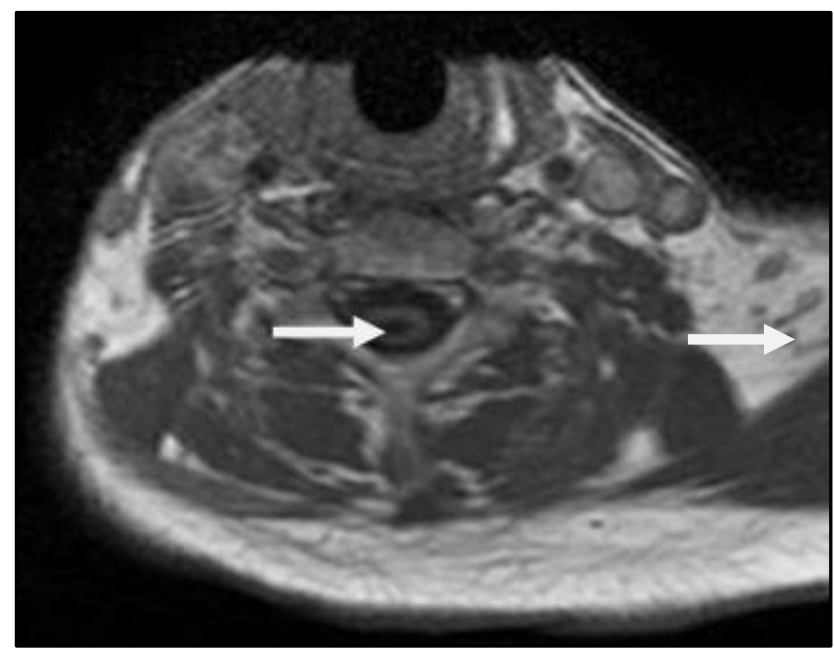

Figure 3. Cut section of the MRI cervical spine showing cavitation of the spinal cord with compression of the spinal cord

\section{DISCUSSION}

Syringomyelia is a neurological disease affecting the spinal cord with predilection to the cervical spinal cord. It has a varied incidence with 8 in 100000 in the western countries and lesser incidence in the eastern countries. It more often affects males compared to females. Causes of syringomyelia include inherited and acquired disease. The inherited cause is due to Arnold-Chiari malformations (Downward displacement of cerebellar tonsils into the foramen magnum). The acquired causes include post traumatic, meningitis, tumours and haemorrhage. Some articles of tuberculoma association with syringomyelia have been reported. ${ }^{1}$

It is a chronic progressive degenerative disorder of the spinal cord with cavitation of the central part of the spinal cord in the cervical region but may extend upwards into medulla oblongata and pons or downwards to the thoracic and lumbar regions. The exact pathogenesis is still not clearly understood but obstruction to the flow of the cerebrospinal fluid has been postulated as the pathology. The usual age of presentation is $25-40$ years of age. ${ }^{1}$

Clinical symptoms and signs consist of weakness and wasting of the upper limbs with UMN features in the lower limb due to involvement of pyramidal tract. Patients characteristically present with 'dissociative sensory loss' with loss of pain and temperature with preserved touch sensations over the upper limb and trunk. Patients may develop Horner's syndrome due to involvement of the cervical sympathetic chain. Clubbing is a feature of syringomyelia. Patients also present with ulcers in hand due to sensory loss. Patients also may have neck pain with extending into the shoulder and arm. Bladder and bowel involvement occurs late in the disease. 1,2

Syringobulbia is extension of the syrinx into the medulla and pons. It presents with sensory loss of the face (Onion peel appearance). Patients may present with dysphagia and wasting and fibrillation of the tongue due to involvement of lower cranial nerves (IX, X and XII nerves).

Differential diagnosis include amyotrophic lateral sclerosis, chronic inflammatory demyelinating polyradiculoneuropathy, brain stem syndromes, ankylosing spondylitis and cervical spondylosis. Diagnosis is by the 
clinical findings and confirmed by imaging techniques. Computed tomography and Magnetic resonance imaging (MRI) are useful in diagnosis but MRI is the gold standard. ${ }^{3}$

Treatment is mostly surgical. Medical management includes use of pregabalin and NSAIDS for pain and neurorehabilitation. Surgery includes suboccipital and cervical decompression; laminectomy and syringotomy (Dorsolateral myelotomy). Shunt procedures have also been done. Terminal ventriculostomy can be done; however, it is not suitable for Chiari malformations. Neuroendoscopic surgeries are also tried. But most of these procedures are not much satisfactory. ${ }^{3,4}$

\section{CONCLUSION}

To conclude, any patient with symptoms of dissociative sensory loss should be screened for syringomyelia. A careful history is needed to find the cause and treat. Early diagnosis by imaging (MRI) and surgical treatment may prevent disability.

\section{REFERENCES}

1. Batzdorf U. Syringomyelia related to abnormalities of the craniovertebral junction. Baltimore: Williams \& Wilkins 1991.

2. Anson, John A, Benzel EC, et al. Syringomyelia and the Chiari Malformation. Rolling hills, IL: American Association of Neurological Surgeons, 1997.

3. Brodbelt AR, Stoodley MA. Post traumatic syringomyelia: a review. J Clin Neurosci 2003;10(4):401-8.

4. Todar DR, Harrison TM, Milhorat TH. Pain and syringomyelia: a review. Neurosurg Focus 2000;8(3):E11. 